\title{
Favorable and Unfavorable Characteristics of EFL Teachers Perceived by University Students of Thailand
}

\author{
Jun Chen \\ Department of Foreign Languages, Qiannan Normal University for Nationalities \\ Duyun 558000, Guizhou, China \\ E-mail: darrenchenjun@163.com
}

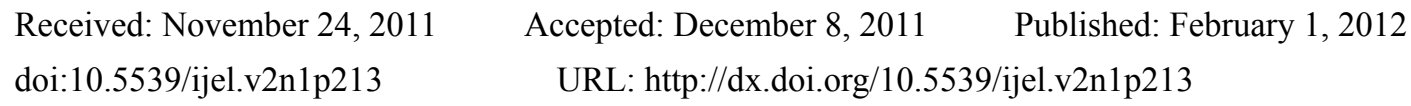

\begin{abstract}
Teachers play pivotal roles in EFL classrooms. Characteristics of EFL teachers may affect students' attitudes and motivations to language learning. The effective/good characteristics of the EFL teachers perceived by the students have been extensively investigated by the previous research works. However, the perceptions of the students from different backgrounds to EFL teachers may vary in different learning settings. In addition, the research works on both favorable and unfavorable characteristics of EFL teachers are comparatively scarce. This study aimed to investigate the favorable and unfavorable characteristics of the EFL teachers perceived by Thai university students. The data were collected from 60 students at Vongchavalitkul University. Open-ended questionnaires and semi-structured interviews were used as the main instruments for data collection. Useful information about EFL teachers' personal trait-related characteristics and classroom teaching-related characteristics emerged from the data. The information is very useful and beneficial for the EFL teachers to reflect their personal characteristics and reconsider their classroom teaching, which may be very helpful for them to do some adjustment and preparation in their teaching to achieve better education results.
\end{abstract}

Keywords: Students' perceptions, Teachers' characteristics, EFL teachers, Favorable, Unfavorable

\section{Introduction}

\subsection{The importance of EFL teachers' characteristics}

The teacher is one of the main factors that have a lot of influence on students' achievement. In addition to the teacher's knowledge about the subject matters, other characteristics of the teacher such as teaching skills, teaching styles and personal traits will also impact the students' learning attitudes, motivation and the learning outcomes to some extent. According to Adams and Pierce (1999), "having many years of experience doesn't guarantee expert teaching; experience is useful only when the teacher continually engages in self-reflection and modifies classroom techniques to better serve the needs of students". Apart from good teaching skills that teachers need to have, personal traits are also equally important because they also play a vital role in the success of learning, as stated by Thompson (2008) that building and maintaining relationship in classroom was necessary. The teacher seemed to take the key role in facilitating the students' learning and the characteristics of the teacher may influence the students' learning process to some extent as well (Murray, 1991). Prabhu (1990) pointed out that the characteristics of EFL teachers with positive attitudes and enthusiasm strongly correlated with increasing rapport between students and teachers, and appeared to promote productive learning. This indicates that the teacher's characteristics can both encourage and discourage the students' learning.

In respect of the classroom atmosphere, this matter may be influenced by the teacher's characteristics as well. Kumaravadivelu (1992) affirmed that the teacher who was described as being purposeful, task-oriented, relaxed, warm, supportive, and had a sense of humor would be able to establish a positive, learnable, and teachable classroom atmosphere. Kumaravadivelu (1992) added that the teacher who had been equipped with pedagogical and professional characteristics would not be enough to establish a productive classroom atmosphere.

Possessing some kinds of characteristics such as knowing well in subject maters, being able to explain the subject matters clearly seems to be insufficient to be an effective EFL teacher. EFL teacher should also possess some other particular characteristics such as being relaxed, warm, and supportive and so on, which might facilitate the students' learning and promote good classroom atmosphere as well. 


\subsection{The previous studies}

As the teacher factor matters to students' learning, a large number of research works have been carried out on the characteristics of EFL teachers, aiming at investigating the perceptions of teachers and the students towards the EFL teachers. The majority of the studies mainly aimed at examining what "effective" or "good" characteristics of EFL teachers were. Some contrastive studies have been conducted to explore the perceptions of the teachers and the students. For example, Park and Lee (2006) investigated the characteristics of effective EFL teachers perceived by 169 teachers and 339 students in Korea with self- report questionnaire consisting of three categories, i.e. English proficiency, pedagogical knowledge, and socio-affective skills. The results revealed that the teachers perceived English proficiency the most important, whereas the students ranked pedagogical knowledge the highest. Park and Lee (2006) pointed out that the discrepancy of perceptions held by the two parties might predispose the students to resist the teaching methods and approaches used by their teachers and, in turn, could lead to ineffectiveness in their learning. Similarly, Shishavan and Sadeghi (2009) characterized qualities of an effective EFL teacher as perceived by Iranian EFL teachers and students. The tailor-made questionnaires were administered to $59 \mathrm{EFL}$ teachers and 215 students. The findings revealed that EFL teachers and students held different views toward some characteristics of an effective EFL teacher. Teachers perceived the features like mastery of the target language, good knowledge of pedagogy and the use of particular techniques and methods as well as a good personality to make an effective EFL teacher. Whereas students gave more weight to characteristics relating to a teacher's personality and the way the teacher behaved toward his/her students. More recently, Wichadee (2010) investigated the characteristics of effective EFL teachers as perceived by 400 Bangkok University students and 53 full-time EFL teachers. Data were obtained through a questionnaire which had been designed based on Park and Lee's concepts (2006). The findings were based on four categories, i.e. English proficiency, pedagogical knowledge, organization and communication skills, and socio-affective skills. The results showed that Bangkok University students defined an effective EFL teacher as those with good preparation, effective communication ability and a pleasant personality. This contrasted with the EFL teachers, who believed that having good English language proficiency was the most important for their job.

Some researches only focused on the students' perceptions toward the effective/good EFL teachers (Chen \& Lin 2009; Barnes, 2010). Chen and Lin (2009) investigated Chinese students' perceptions of the characteristics of effective EFL teachers. The data were obtained through a 50-item questionnaire with 198 students in Tainan area. The results revealed that the instructional competence, personality, and teacher-student relationship aspects were all important to be an effective EFL teacher. However, personality and teacher-student relationship were considered more important than instructional competence. More recently, Barnes (2010) examined the students' beliefs about the attributes of effective EFL teachers. 105 first year Korean university students taking EFL classes at a women's university in Korea were asked to write the attributes of effective EFL teachers in their own language. The results of the study were framed under five categories including rapport, delivery, fairness, knowledge and credibility, and organization and preparation. Students considered rapport and delivery as very important characteristics of an EFL teacher. Particularly, rapport attributes were viewed as the most important in Korean university contexts where students had anxiety in English language learning.

The reviewed research works demonstrate that there are differences in how the students perceive the characteristics of the EFL teachers. The perceptions about the characteristics of EFL teachers may depend upon the settings in which teaching and learning occur.

Since EFL teachers' characteristics may affect how students perceive the subject matter, the investigation on students' perceptions towards the characteristics of EFL teachers will be very useful to contribute a better understanding in students' perceptions about the characteristics of their EFL teachers who may affect the students' learning experience towards the foreign language courses. To the best knowledge of the researcher, no previous studies in Thailand have been conducted to explore both the favorable and unfavorable characteristics of EFL teachers. The purpose of the study was to shed some light on the characteristic of EFL teachers from the perspective of the students regarding the two aspects. Above all, for Vongchavalitkul University students, perceptions of this matter have never been investigated before. With these reasons, the researcher would like to sort out what favorable and unfavorable characteristics of EFL teachers as perceived by the students with the hope that the investigation would bring about some benefits and indications to the EFL teachers and help them do some adjustment in their teaching and create more productive atmosphere in the classroom.

\section{Methodology}

\subsection{Participants}

The participants in this study were $60 \mathrm{EFL}$ undergraduate students in Vongchavalitkul University chosen by purposive sampling and stratified sampling. They were science-oriented major students from the faculties of 
Engineering, Nursing Science and Public Health. To keep the balance, 20 students were selected from each faculty, among them half were males and half were females, and each 5 students came from each grade (from Grade 1 to Grade 4).

\subsection{Instruments}

Two instruments were used in this study: an open-ended questionnaire and a semi-structured interview. The questionnaire consisted of two parts: the first part was about the respondents' background information including gender, faculty and English language ability. The second part contained 10 questions. The first four were warm-up questions concerning English language studies, and the last six questions were all about characteristics of English language teachers whom the students wanted to study with or avoided studying with. The draft of the questionnaire was examined and verified by a specialist and two $\mathrm{PhD}$ students of English language studies and then it was translated into Thai, which aimed to let the students understand the questions well and answer them correctly. The semi-structured interview took the same questions as in the questionnaire with the purpose of eliciting richer and deeper information.

\subsection{Data collection}

The open-ended questionnaires were collected from 60 undergraduate students at Vongchavalitkul University in the first semester of academic year 2011. Before the students started answering the questionnaires, the researcher gave a brief instruction on how to respond them. They were told that there were no right or wrong answers and they just answered the questions according to what they really thought. And also they could ask the researchers immediately if they had any questions. The subjects finished the questionnaire within 20 minutes on average.

For the semi-structured interviews, the researcher chose 6 students from the 60 participants with the aim to get more sufficient and in-depth information. They were individually interviewed for about half an hour and were allowed to respond flexibly to the ten questions. The interviews were conducted in Thai with the help of a Thai $\mathrm{PhD}$ student of English language studies, who was the researcher's classmate. The interviews were recorded and the were transcribed into Thai, and then translated into English.

\subsection{Data analysis}

The data were analyzed by using coding, including open coding, axial coding and selective coding. First, the researcher looked through the data to get a whole picture of what the participants reported. The researcher looked at each questionnaire and each transcription of the interviews in great details and picked out the statements concerning with the characteristics of EFL teachers as perceived by the university students. Altogether, there were 357 statements emerging from the data, among which 226 were the characteristics that the students favored and 131 were the characteristics that students did not favor. After the open coding, it came to the axial coding step. The researcher started to look at similarities and differences among these 357 statements, which then were grouped into 34 items according to the repetition or similarities of the statements. When coming to the selective coding step, these 34 items were regrouped into 9 bigger categories, and at last the 9 categories were grouped under two main themes.

\section{Results}

Based on the analyses of questionnaire and interview data, the researcher arrived at the following findings. In order to facilitate the description, Q and I were used to represent questionnaire respondents and interviewees respectively. For example, Q2 represented the second questionnaire respondent, and I5 represented the fifth interviewee. The results would be reported from two main themes: personal trait-related characteristics and classroom teaching-related characteristics.

\subsection{Personal trait-related characteristics}

Personal trait-related characteristics included emotion, kindness, fairness, lenience and responsibility, etc. The respondents mentioned such characteristics frequently. It showed that the students really cared about these characteristics of the teachers.

\subsubsection{Emotion}

Emotion referred to the teacher's sense of humor, temper and patience, etc. Some students (e.g. Q36, Q36, I37, I38, and I39) reported that they favored the EFL teacher who had a sense of humor. They favored the teacher who was humorous and could say some jokes in the teaching process to make the students feel easy and relaxed in the classroom. This could make the students actively involve in the study and have enthusiasm for the study. The students (e.g. Q3, Q49, Q53, Q28, Q29, Q35, Q17, and Q9) said that a good language teacher should have a good temper and should be calm, should be in a good mood and should not get angry and annoyed easily. 
Some students (e.g. Q17, Q24, Q28, and Q29) showed that they didn't want to study with the EFL teacher who was hot tempered and easy to get angry. They also didn't like a teacher who often scolded and complained students. According to the respondents, the teacher should not scold or even shout at students when they made mistakes. The teacher should help the students find the reasons why they made such mistakes and help them correct the errors.

\subsubsection{Kindness}

Kindness was composed of the teacher's kindness, friendliness, politeness to the students. Most of students (totally 52 students) believed that a good EFL teacher must be very kind, polite and friendly. The teacher should not be cruel to the students. To them, a good EFL teacher should be friendly and easy-going. The students favored the teacher who was polite and spoke with smiles. Some students (e.g. Q8, Q13, Q15, Q23, Q31, Q32, Q57, and Q59) said that a good language teacher should understand the students, which included understanding the students' feelings, thoughts, backgrounds, language skills and abilities. A favorable teacher should know how to care for and entertain the students. The teacher should not only require the students to respect him/her, the teacher should also treat the students in kind manners (e.g. I36, Q54, Q23, Q25, and Q28).

For the negative aspects, unkind and cruel EFL teachers were not the preferred ones to the respondents (e.g. Q4, Q8, Q9, Q53, Q57, Q23, and Q26). The teachers who were impolite (e.g. Q50, Q37, Q50, I37), who did not care about the students (e.g. Q54, Q29), who did not understand students' feelings, thoughts, abilities and language levels (e.g. Q1, Q8, Q15, Q32, I36, Q57 and Q47), who did not treat students politely (e.g. I38), and who liked to punish students (e.g. Q55) were distasted by the students.

\subsubsection{Fairness}

Fairness was inclusive of the equality and impartiality. A few students (e.g. Q44, Q53 and Q57) claimed that a good language teacher should pay attention to everybody and should not only care about the students with good achievements. The teacher should treat the students equally and have no bias to them.

Some students (e.g. Q44, Q53, and Q57) did not favor the teacher who treated the students unequally. They disrelished the teacher who only paid attention to some certain students and ignored the others. To them, a teacher with bias was an unfavorable one.

\subsubsection{Lenience}

Lenience was emphasized by some students. The students (e.g. Q3, I36, I38, Q48, and Q58) expressed that a preferred EFL teacher should not be too strict and serious in the teaching. Some flexibility and lenience are also very important and necessary to an effective teacher. From the point of view of the students, the teacher could be strict sometimes but should not be strict and serious all the time.

Many students (e.g. Q1, Q5, Q10, I36, I38, Q42, Q45, Q26, Q30, Q33, Q34, and Q39) reported that they disliked the teacher who was too strict and serious. The students expressed that they didn't want to study with a teacher who was strict and serious all the time without flexibility. The teacher who was too strict about scores, assignment and mistakes, etc. was an unfavorable one.

\subsubsection{Responsibility}

Responsibility was a very important criterion of a good language teacher. It involved teaching intention and teaching preparation. Some students (e.g. Q29, Q37, Q39, Q47, Q51, and Q58) stated that a good language teacher must have strong intention to teach. The teacher should be industrious, enthusiastic and responsible for the teaching. Well prepared and organized teaching plan was the assurance of successful teaching. Patience in term of explaining the subject matter was repeatedly mentioned by the respondents. Apart from these, the students showed their preference to the teachers who were willing to teach students individually.

Some students (e.g. Q29, Q46, and Q51) showed their negative attitudes to the teachers who were lazy to teach and went in to the classroom without any preparation. They loathed the teachers who had no intention to teach and no patience to explain the subject matters. Teachers who gave assignments to the students without explanation and direction would also make the students feel dissatisfied.

\subsection{Classroom teaching-related characteristics}

This part included aspects of lesson delivery, language used in teaching, classroom activity organization and classroom atmosphere creation.

\subsubsection{Lesson delivery}

Lesson delivery was inclusive of ways of presentation, techniques and abilities to make things comprehensible, 
techniques and abilities to deal with teaching content, assignment and error corrections, etc. Skills and techniques of lesson delivery were very crucial for a favorable teacher. An EFL teacher who had good teaching skills and techniques were adored by the students (e.g. I36, Q48, Q49, Q40, Q41, Q52, Q54, Q30, Q31, Q28, etc). The students believed that the teaching methods of a favorable language teacher must be flexible. The teacher could make the teaching comprehensible, understandable and interesting (totally 29 respondents). For example, a favorable teacher should use proper teaching aids and samples, give good examples, start from the basic to the difficult points, explain from the simple to the complex matters, etc. Good language teachers should have the abilities to make the students enthusiastic in the study and lead them to discover new knowledge (e.g. Q8, Q19, Q21, Q37, Q 46, and Q52). The students said that they liked the teacher who taught at a proper speed and could adjust their teaching speed according to students' accepting abilities. The students also favored a teacher who did not just follow the text book. They hoped the teacher could teach something useful in the real life that they could apply in the daily life (e.g. I38, Q38, Q37 Q30, and Q17). Some students claimed that they hoped the teacher to teach what was relevant to the subject and did not talk about other things that had nothing to do with the subject matter. (e.g. Q2, Q5, Q17, Q21).

The students were disgusted with the teacher who didn't have teaching techniques and skills to make things comprehensible to students (such as Q30, I41, Q2, Q5, Q6, Q8, Q9, Q13, Q15, Q17, 43, Q50). They did not like the teachers who always made things complex and confusing, made the teaching incomprehensible and made the students get lost (e.g. Q2, Q5, Q6, Q8, Q9, Q13, Q15, Q17, etc.). They did not favor the teacher who spoke and taught very fast (e.g. Q5, Q7, Q16, Q19, Q20, and Q47). The teacher who talked about the things which were not relevant to the subject matter was not welcomed. The teaching which just followed the text book was unsatisfactory to the students (e.g. Q2, Q48, Q49, Q28, Q30, Q37, Q38, and I37). From the students' perceptions, the teacher who never praised and encouraged students was unfavorable (e.g. Q36, I41, and I37). The students revolted the rote memorizing under the requirement of the teacher (e.g. Q27, Q29, Q36, and Q53).

\subsubsection{Language used in teaching}

Some students claimed that they would like to learn with the EFL teacher who spoke both English and Thai (e.g. Q6, Q7, Q16, Q17, Q26, Q43, Q57, and Q59). They believed that if the teacher spoke English and Thai while teaching, they could understand better and were willing to learn. Regarding to the teachers' nationalities, some students said that they hoped to study with an English native speaker so that they could get some real exposure to the language (e.g. Q13, Q27, Q32, and Q35). But some students hoped to study with a Thai teacher, who would be much easier for them to communicate with (e.g. Q7, Q5, and Q23). For the Thai English language teachers, the students were willing to study with those whose pronunciation was very good. They hoped their language teachers could pronounce as good as or almost the same as the native speakers (Q13 and Q17).

Some students expressed that they were unwilling to study with the EFL teacher who only spoke English in the classroom (Q7, Q11, Q15, and Q57). For the foreign teachers, those who could not speak Thai at all were unpopular to the students (Q33, Q37, and Q45). According to them, if the teachers couldn't speak Thai, it would be very hard for them to understand the difficulties sometimes.

\subsubsection{Classroom activity organization}

Classroom activities were valued by many students (e.g. Q3, Q4, Q9, Q14, Q19, I36, I38, and I37). The students thought that classroom activities played very important roles in the classroom. Good activities could motivate the students to study and make the students actively involved in the study. The students hoped the teacher to organize some good activities to make the study comfy and easy. In this way, they could learn the language knowledge without taking much effort. The students preferred the teacher who had intention and ability to organize different kinds of activities, such as playing games, reading stories, singing songs, and doing some competition activities, etc.

Some students disliked the teacher who just taught on his / her own way and did not organize any activities. They thought this kind of teaching as an old fashioned and traditional method. It was not student-centered but teacher-centered. The students just followed and listened to the teacher and they were very passive and had little freedom in the classroom (e.g. Q14, Q16, Q18, I36, and I38).

\subsubsection{Classroom atmosphere creation}

Lots of students (27 respondents) mentioned the importance of classroom atmosphere. The students reported that they hoped to study in an entertaining, comfortable, relaxing and pleasant atmosphere. The students expressed their predilection to the teaching which was enjoyable and not stressful.

The students showed their distaste to the teacher who was too strict and serious and make the classroom 
atmosphere tedious and boring. Which would make the students feel stressful and nervous (e.g. Q5, Q6, Q12, Q41, Q49, Q43 and Q49).

\section{Discussion}

After the full report of the results, some important points needed to be further emphasized and discussed. Personal qualities of teachers were important elements to good teaching (Trice \& Harris, 2000). Some other studies in this field also shared the similar discovery that most of the students preferred the EFL teachers with good personal traits or qualities. Data collected in this study revealed that the students attached importance to EFL teachers' personal trait-related characteristics. It was consistent with the findings of Shishavan and Sadeghi (2009), which revealed that the Iranian students concerned about the teacher' personalities and how the teachers behaved to them.

According to McDermott \& Rothenberg (2000), students preferred the teachers with a sense of humor and the teachers who made learning fun. In this study, the students mentioned that they liked to study with the teacher who had a sense of humor. If a teacher had a quick wit and the ability to break the ice in difficult situations with the use of humor, which was an extremely valuable asset, it could make the students feel easy and relaxed in the classroom.

Of the sixty students investigated, almost all of them emphasized the importance of the English language teachers' kindness. It seemed that the students had a high agreement in this aspect. They believed that a good/effective EFL teacher should be kind, friendly, and understanding to the students and the students would like to study with such kind of teacher. Murray (1991) and Prabhu (1990) pointed out that the characteristics of EFL teachers with positive attitudes to their students would increase rapport between students and teachers, which would promote productive and successful learning. To English language teachers, this aspect can not be neglected. English language teachers should pay attention to their attitudes towards the students.

The ways and techniques of lesson delivery were frequently mentioned by the students. More than half of the students expressed that they favored the teachers who had good teaching skills and techniques to make the teaching content clear and comprehensible. Students expected the teachers to be deeply knowledgeable and have the ability to deliver the subject matter to them in meaningful and engaging manners. Half of the students said that they were unwilling to study with the teachers who didn't have or didn't care about good teaching methods and techniques. This was in line with Park and Lee (2006), who studied the students' perceptions about effective characteristics of EFL teachers in Korea. The results showed that the Korean students placed the most important characteristic of the teacher knowledge on the pedagogical knowledge. Apart from the personality trait-related characteristics, the participants under this study concerned about teaching skills and techniques of the teachers a lot. Broder and Dorfman (1994) asserted that "while knowledge is important, the ability to deliver that knowledge equally, if not more, important". Broder and Dorfman (1994) added that students would question a teacher's content knowledge quotient if the method of presentation was unsatisfactory to them. Therefore, it is necessary for the EFL teachers to strengthen the training in language teaching methods.

It was interesting to discover that some students liked to study with the teachers who spoke English and Thai in the classroom. Some students preferred to study with the foreign teachers who could speak Thai. According to them, if the teacher spoke English and Thai while teaching, they could understand the teaching better and would have higher motivation to learn.

The data also revealed that some students would like to study with Thai teachers, but some favored the foreign teachers. For the students who favored foreign teachers, they believed that they could experience authentic English with native speakers and this could improve their English language proficiency greatly. For the students who favored Thai teachers, they expressed that it would be less stressful and less nervous to study with the Thai teachers. They could ask the teachers questions in Thai if they could not really understand. For this aspect, there were some similarities between this study and Chen's study (2008). Chen (2008) investigated Chinese college students' perceptions of their non-native English teachers. The findings revealed that the best teacher of English was a native speaker with the belief in the superiority in language proficiency and competency. However, non-native English teachers had certain advantages by being able to anticipate their students' problems and empathize with difficulties. This phenomenon probably implied that the students' English language levels were comparatively low and could not understand the teaching all in English. So in the practical teaching, the teacher must consider the students' language levels and use some compensating ways to help the students to understand, such as speaking slowly, using simple words, simple sentences and using mother tongue at proper time.

Another important factor emphasized by the students was the classroom atmosphere creation. More than half of the students stated that they liked the teachers who could create pleasant, comfortable and relaxing classroom 
atmosphere. They disliked the teacher who made the classroom atmosphere depressing, dreary and tedious. The students said that good classroom atmosphere would be helpful for students to overcome fears, feel comfortable, and participate more, which then could motivate students to continue their study. To create a good classroom atmosphere, there must be a rapport between the teacher and the students. As Barnes (2010) stated, rapport was seen by some students as having a significant effect on learning. Students thought that rapport affected class atmosphere, which in turn affected motivation and learning.

\section{Conclusion}

This study investigated the favorable and unfavorable characteristics of EFL teachers as perceived by the university students of Thailand. These characteristics were grouped into personal trait-related and classroom teaching-related characteristics. The personal trait-related characteristics included emotion, kindness, fairness, lenience and responsibility, etc. and the classroom teaching-related characteristics were concerned with aspects of lesson delivery, language used in teaching, classroom activity organization and classroom atmosphere creation, etc. The information emerged from the data will be very useful and beneficial for the EFL teachers to do some self-reflection about their own characteristics from the perspective of the students. Consulting the information of the study, the EFL teachers can do some changes and adjustment in their future teaching to achieve better education results. Knowing about what characteristics the students like and dislike can help the EFL teachers to some preparation and adjustment before going into the classroom. To do so, the teachers may bring more productive atmosphere to the classroom settings and presuppose the students to reach their learning achievements in the end.

There are still some limitations for the present study. The data for the study only included 60 science-oriented major students from four faculties in Vongchavalitkul University, which was not so representative for Thai university students. Future research can be conducted to investigate more students from more different majors and different universities to check whether other university students hold the same beliefs or not.

\section{References}

Adams, C. \& Pierce, R. (1999). Characteristics of effective teaching. [Online] Available: http: // www. naeyc. org /files/yc/file/200803/BTJ_Colker (September, 2011)

Barnes, B. D. (2010). The Attributes of Effective Lecturers of English as a Foreign Language as Perceived by Students in a Korean University. Australian Journal of Teacher Education, 35(1): 139-152.

Broder, J. M. \& Dorfman, J. H. (1994). Determinants of teaching quality: What's important to students? Research in High Education, 35(2), 235-249. http://dx.doi.org/10.1007/BF02496703

Brown, H. D. (2001). Teaching by principles (2nd ed.). White Plains, NY: Pearson.

Chen, X. (2008). A survey: Chinese college students' perceptions of non-native English teachers. CELEA Journal, 31(3): 75-82.

Chen, Y. \& Lin, S. (2009). Exploring Characteristics for Effective EFL Teachers: From the Perceptions of Junior High School Students in Tainan. STUT Journal of Humanities and Social Sciences, 2: 219-249.

Kumaravadivelu, B. (1992). Macro-strategies for the second/foreign language teachers. Modern Language Journal, 75: 41-49. http://dx.doi.org/10.1111/j.1540-4781.1992.tb02577.x

Lee, J. J. (2010). The Uniqueness of EFL teachers: Perceptions of Japanese Learners. TESOL Journal, 1(1): 23-48. http://dx.doi.org/10.5054/tj.2010.214881

McDermott, P. \& Rothenberg, J. (2000). The characteristics of effective teachers in high poverty schools: Triangulation our data. Paper presented at the annual meeting of the American Educational Research Association, New Orleans. (ERIC Document Reproduction Service No. ED442887). Educational Research Association, New Orleans.

Murray, H. G. (1991). A time for local perspectives. In J. Murphy and P. Byrd (Eds.), Understanding the course we teach: Local perspectives on English language teaching (pp.3-10). Ann Arbor: University of Michigan Press.

Park, G. \& Lee, H. (2006). Characteristics of effective teachers perceived by high school teachers and students in Korea. Paper presented at 19th English Australia Education Conference, Perth, Australia.

Prabhu, N. S. (1990). There is no best method-Why? TESOL Quarterly, 24: 232-338. http://dx.doi.org/10.2307/3586897

Shishavan, B. H. \& Sadeghi, K. (2009). Characteristics of an Effective English Language Teacher as Perceived by Iranian Teachers and Learners of English. English Language Teacher, 2 (4): 130-143.

Thompson, S. (2008). Defining a good teacher simply! Modern English Teacher, 17(1): 5-14

Trice, A. D. \& Harris, C. M. (2001). Perceptions of teachers' qualities by American and Bulgarian preservice teachers. Education, 122(2): 381-385.

Wichadee, S. (2010). Defining the effective English language teacher: Students' and teachers' perspectives. In Stoke, A.M (Ed.), JALT2009 Conference Proceedings. Tokyo: JALT. 